\title{
Antioxidant and $\alpha$-Glucosidase Inhibitory Activities Guided Isolation and Identification of Components from Mango Seed Kernel
}

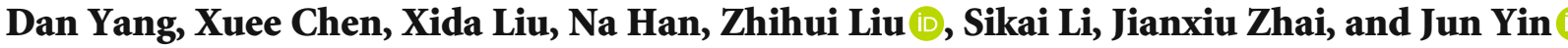 \\ Department of Pharmacognosy and Utilization Key Laboratory of Northeast Plant Materials, School of Traditional \\ Chinese Medicine, Shenyang Pharmaceutical University, Shenyang 110016, China \\ Correspondence should be addressed to Zhihui Liu; liuzhihuishenyang@163.com and Jun Yin; yinjun826@sina.com
}

Received 21 August 2020; Accepted 28 November 2020; Published 29 December 2020

Academic Editor: Gianna Ferretti

Copyright @ 2020 Dan Yang et al. This is an open access article distributed under the Creative Commons Attribution License, which permits unrestricted use, distribution, and reproduction in any medium, provided the original work is properly cited.

\begin{abstract}
In the present study, petroleum ether, dichloromethane, ethyl acetate, and $n$-butanol fractions of mango seed kernel exhibited different degrees of antioxidant and $\alpha$-glucosidase inhibitory activity. Thus, quantitative and qualitative analysis of the petroleum ether fraction was conducted by GC-MS. Among identified components, four unsaturated fatty acids had never been reported in natural products before, together with 19 known components. In addition, 17 compounds were isolated and elucidated from other active fractions. Compounds 2, 9, 15, and 17 were isolated for the first time from Mangifera genus. Compounds 1 and 2 exhibited prominent DPPH radical scavenging and $\alpha$-glucosidase inhibitory effects. In order to further explore their mechanism of $\alpha$-glucosidase inhibition, their enzyme kinetics and in silico modeling experiments were performed. The results indicated that $\mathbf{1}$ inhibited $\alpha$-glucosidase in a noncompetitive manner, whereas $\mathbf{2}$ acted in a competitive manner. In molecular docking, the stability of binding was enhanced by $\pi-\pi$ T-shaped, $\pi$-alkyl, $\pi-\pi$ stacked, hydrogen bond, and electrostatic interactions. Thus, compounds $\mathbf{1}$ and $\mathbf{2}$ were determined to be new potent antioxidant and $\alpha$-glucosidase inhibitors for preventing food oxidation and enhancing hypoglycemic activity.
\end{abstract}

\section{Introduction}

Type 2 diabetes is a chronic and complex metabolic disease characterized mainly by hyperglycemia, insulin resistance, and insufficient insulin secretion [1]. When carbohydrates are swallowed, dietary polysaccharides are absorbed by the hydrolysis effects of enteral $\alpha$-glucosidase to obtain free monosaccharides [2]. Free monosaccharides assimilated in the blood can lead to hyperglycemia caused by type 2 diabetes [3]. One of the diabetes treatments is to inhibit the enzyme activity of $\alpha$-glucosidase to minimize the formation of blood glucose. $\alpha$-Glucosidase inhibitors extend the overall carbohydrate digestion time and decrease the absorption of glucose, which slow postprandial glucose elevation [4]. Several drugs, $\alpha$-glucosidase inhibitors, such as voglibose, acarbose, and miglitol, are now available to treat the patients who suffer from postprandial hyperglycemia. However, a long-term use of these inhibitors has been associated with severe side effects, such as diarrhea and vomiting [5]. Hyperglycemiainduced oxidative stress is implicated in the onset and progression of diabetes and, if left untreated, can lead to severe complications [6]. Free radicals and reactive oxygen species are products of normal cellular metabolism and are extremely reactive and potentially damaging transient chemical species [7]. Numerous studies showed that over generation of free radicals and reactive oxygen species could be harmful to human health and trigger many diseases, such as cancer, arteriosclerosis, inflammatory disorders, and aging processes [7]. Therefore, the development of highefficiency and low-toxicity antioxidant and $\alpha$-glucosidase inhibitors from natural resources has become one research hotspot. 
Mango (Mangifera indica L.) is one of the most popular fruit worldwide, which belongs to the Anacardiaceae and grown in many places around the world, particularly in tropical and subtropical countries. This fruit is available as a dietary supplement due to their high nutritional value, such as providing dietary fiber, fats, proteins, carbohydrates, and phenolic compounds, which are vital to human growth, development, and health [8]. Mango seed kernel, a traditional Chinese medicine, is widely available and used in China, and its bioactivities had been recorded. Chaianun and Praphan [9] indicated that the 95\% ethanol extracts from two different kinds of mango seed kernel, namely, Kaew and Choke-Anan, both had good $\alpha$-glucosidase inhibitory activity with $\mathrm{IC}_{50}$ values of $163.19 \pm 2.33$ and 113.51 $\pm 5.85 \mu \mathrm{g} / \mathrm{mL}$, respectively. Emmanuel, Ganiyu, Afolabi, Aline, and Margareth [10] had demonstrated that the methanol extract of mango seed kernel could significantly inhibit the activity of $\alpha$-glucosidase. Although it was used for centuries as a traditional folk prescription in China, there are few studies on chemical components in mango seed kernel and bioactivities of its monomeric compounds. Meanwhile, no investigations on the composition and activity of its petroleum ether fraction have been previously reported.

Consequently, a bioassay-guided fractionation method was used by us to research the bioactive components in mango seed kernel. Its crude extract was successively partitioned with petroleum ether, dichloromethane, ethyl acetate, and $n$-butanol, respectively. The ethyl acetate and $n$-butanol fractions showed significant DPPH radical scavenging activity. Petroleum ether, dichloromethane, and ethyl acetate fractions revealed moderate $\alpha$-glucosidase inhibitory activity. These finding prompted us to perform a detailed chemical evaluation, leading to the identification of 23 components from the petroleum ether fraction by LC-MS and the isolation and purification of 17 compounds from other active fractions of mango seed kernel. Antioxidant and $\alpha$-glucosidase inhibitory activities of the identified components from the petroleum ether fraction had been reported in many references. Bioactivities of 13 isolated compounds from other active fractions were tested, and compounds $\mathbf{1}$ and $\mathbf{2}$ were found to be active. The enzyme kinetic parameters of active compounds were also determined. The results of the molecular docking were used to visualize how they bind to $\alpha$-glucosidase, providing insights into $\alpha$-glucosidase inhibition mechanism of the active compounds.

\section{Materials and Methods}

2.1. Chemicals and Reagents. 1D NMR spectra was measured on a bruker ARX-600 spectrometer using tetramethylsilane as an internal standard. Absorbance data were recorded on KHB-ST-360 ELIASA (Shanghai Kehua Bio-engineering Co., Ltd.). Preparative chromatography was performed on a CHEETAH Flash MP200, while semipreparative HPLC was performed on a Shimadzu LC-10A spectrophotometer, using a Welch XB-C18 semipreparative column $(5 \mu \mathrm{m}, 10 \times 250$ $\mathrm{mm})$. Column chromatographies (CC) were carried out over silica gel (200-300 mesh, Qingdao Haiyang Chemical Co.,
Shandong, China), ODS (50-100 mesh, YMC, Co., Ltd., Japan), and Sephadex LH-20 (Pharmacia, USA). Gas chromatography mass spectrometry (GC-MS) spectra were recorded on a Shimadzu (TQ-8040) series GC-MS system (n). $\alpha$-Glucosidase from Baker's yeast was purchased from Shanghai Yuanye Biotechnology Co., Ltd. Acarbose was purchased from Hangzhou Zhongmei Huadong Pharmaceutical Co., Ltd. $p$-NPG ( $p$-nitrophenyl- $\alpha$-D-glucopyranoside) was purchased from Shanghai McLean Biochemical Technology Co., Ltd. DPPH (1,1-diphenyl-2-picrylhydrazyl) and anhydrous $\mathrm{Na}_{2} \mathrm{CO}_{3}$ were obtained from Sigma Aldrich (St. Louis, MO, USA). Deuterium generation reagents were obtained from Cambridge Isotope Laboratories, Inc. Dipotassium phosphate was obtained from Junsei Chemical Co., Ltd. (Tokyo, Japan). Monopotassium phosphate was purchased from Yakuri Pure Chemicals Co., Ltd. (Osaka, Japan), and all other chemicals and solvents of analytically pure and HPLC grade were purchased from Shenyang Lebo Reagent Co. Ltd (Shenyang, China).

2.2. Plant Material. The seeds of Mangifera indica L. were obtained from Shenyang Guoda Pharmacy Co., Ltd. (Liaoning Province, China, in 2017). The botanical identification was made by Prof. Jun Yin of Shenyang Pharmaceutical University. A voucher specimen (No. 20170920) was deposited in the Research Department of Traditional Chinese Medicine, Shenyang Pharmaceutical University, Shenyang, Liaoning, China.

2.3. Antioxidant and $\alpha$-Glucosidase Inhibitory Activities Evaluation of the Extract and Fractions from Mango Seed Kernel. The seeds of Mangifera indica L. (1 kg) were removed from the shell, which homogenized with a homogenizer. Dried powders $(600 \mathrm{~g})$ of mango seed kernel were exhaustively extracted with $60 \%$ ethanol for $1 \mathrm{~h}(20 \mathrm{~L} \times 2$ times $)$ at room temperature and were concentrated under reduced pressure. The concentrated solution was successively partitioned with petroleum ether, dichloromethane, ethyl acetate, and $n$-butanol.

2.3.1. DPPH Assay. The DPPH radical scavenging activity assay was determined according to the reported method with minor modifications [11]. Briefly, extract and four fractions were dissolved in methyl alcohol at concentrations ranging from 62.5 to $1000 \mu \mathrm{g} / \mathrm{mL}$, which were prepared to mix with a methyl alcohol solution of DPPH $(0.2 \mathrm{mM}, 100 \mu \mathrm{L})$ on a 96-well plate. After that, shaken gently and stood at room temperature for $30 \mathrm{~min}$, the optical density (OD) $517 \mathrm{~nm}$ in each well were determined by a microplate reader. Triplicates of each sample were run, and the mean values were calculated. Ascorbic acid was chosen as positive control. The percentage inhibition (\%) for each sample was calculated by the following formula:

$$
\text { Inhibition }(\%)=\left[\frac{1-\left(\mathrm{Abs}_{\text {samples }}-\mathrm{Abs}_{\mathrm{control}}\right)}{\mathrm{Abs} s_{\text {blank }}}\right] \times 100 \% \text {. }
$$


DPPH solution was replaced by a methanol solution, which was used as control, and samples were replaced by the methanol solution as the black. All the results were expressed as means \pm standard deviation (SD). $\mathrm{IC}_{50}$ values denoted the concentration of the sample required to scavenge $50 \%$ of the DPPH radical.

2.3.2. $\alpha$-Glucosidase Inhibitory Assay. The $\alpha$-glucosidase inhibitory assay was performed on a 96-well plate by using a microplate reader according to the published method [12] with minor modifications. Extract and four fractions were required to dissolve in $5 \% \mathrm{DMSO}$ at the concentrations ranging from 62.5 to $1000 \mu \mathrm{g} / \mathrm{mL}$. In brief, $20 \mu \mathrm{L}$ of $\alpha$-glucosidase $(1.3 \mathrm{U} / \mathrm{mL})$ and $20 \mu \mathrm{L}$ sample were added to $20 \mu \mathrm{L}$ of $0.1 \mathrm{M}$ potassium phosphate buffer ( $\mathrm{pH}$ 6.8). After 5 min incubation at $37^{\circ} \mathrm{C}, 20 \mu \mathrm{L}$ of 4 -pNPG ( $p$-nitrophenyl- $\alpha$-D-glucopyranoside) $(2.5 \mathrm{mM})$ was added and incubated for $15 \mathrm{~min}$; then, $80 \mu \mathrm{L}$ of $\mathrm{Na}_{2} \mathrm{CO}_{3}(0.2 \mathrm{M})$ was added to stop the reaction. The optical density (OD) values were determined using a microplate reader at $405 \mathrm{~nm}$. Triplicates of each sample were run, and the mean values were calculated. Acarbose was used as positive control. The percentage inhibition (\%) was calculated as the following formula:

$$
\text { Inhibition }(\%)=\left[\frac{1-\left(A_{\mathrm{a}}-A_{\mathrm{b}}\right)}{A_{\mathrm{c}}-A_{\mathrm{d}}}\right] \times 100 \% \text {. }
$$

$A_{\mathrm{a}}$ : absorbance of the sample group with enzyme.

$A_{\mathrm{b}}$ : absorbance of the sample control group without enzyme.

$A_{\mathrm{c}}$ : absorbance of the control group without samples.

$A_{\mathrm{d}}$ : absorbance of the blank control group without samples and enzyme.

The $\mathrm{IC}_{50}$ was calculated by using SPSS software.

2.4. GC-MS Analysis of the Bioactive Fraction (Petroleum Ether Fraction) from Mango Seed Kernel. The GC-MS analysis of constitutes in the bioactive fraction (Petroleum ether fraction) of mango seed kernel was carried out on a Shimadzu (TQ-8040) series GC-MS system (n) equipped with an AOC-20i autosampler [13]. The operational process of GC-MS analysis was as follows: rising from $40^{\circ} \mathrm{C}$ to $130^{\circ} \mathrm{C}$ at a rate of $4^{\circ} \mathrm{C} / \mathrm{min}$ and holding for $2 \mathrm{~min}$, rising from $130^{\circ} \mathrm{C}$ to $150^{\circ} \mathrm{C}$ at a rate of $2^{\circ} \mathrm{C} / \mathrm{min}$ and holding for $3 \mathrm{~min}$, rising from $150^{\circ} \mathrm{C}$ to $180^{\circ} \mathrm{C}$ at a rate of $2^{\circ} \mathrm{C} / \mathrm{min}$ and holding for $3 \mathrm{~min}$, and finally enhanced to $210^{\circ} \mathrm{C}$ and held isothermally for $5 \mathrm{~min}$. Chemical constituents were then pointed out based on the mass spectra and retention times with already known compounds in the NIST14 and NIST14s (National Institute of Standards and Technologies, Mass Spectra Libraries, Gaithersburg, MD, USA) [13].

2.5. Isolation and Purification of Compounds in Active Fractions from Mango Seed Kernel. The dichloromethane fraction $(4.2 \mathrm{~g})$ was subjected to a silica gel column (200300 mesh) in gradient elution of mixture solvent composed of petroleum ether-acetone (from 100:10 to $100: 100, v / v$ ) and led to four subfractions (Fr.1-1-Fr.1-4). Compounds 10 $(22.2 \mathrm{mg})$ and $7(2.4 \mathrm{mg})$ were yielded through recrystalliza- tion $(\mathrm{MeOH})$ from Fr.1-2, and the remaining fraction was further purified by semipreparative $\mathrm{HPLC}\left(\mathrm{MeOH}-\mathrm{H}_{2} \mathrm{O}\right.$, $45: 55)$ to obtain compound $\mathbf{1 3}(2.1 \mathrm{mg})$. Fr.1.3 was further separated repeatedly with Sephadex LH-20 $(\mathrm{MeOH})$ to obtain two subfractions (Fr.1.3.1- Fr.1.3.2). Compound 6 $(100.1 \mathrm{mg})$ was obtained through recrystallization $(\mathrm{MeOH})$ from Fr.1.3.1. Fr.1.3.2 was subjected to preparative TLC $\left(\mathrm{CH}_{2} \mathrm{Cl}_{2}\right.$-Acetone, $\left.10: 8\right)$ to obtain compound $8(2.0 \mathrm{mg})$. Fr.1.4 was further separated repeatedly with Sephadex LH$20(\mathrm{MeOH})$ to obtain compound $\mathbf{1 6}(2.3 \mathrm{mg})$.

The ethyl acetate fraction $(19.6 \mathrm{~g})$ was subjected to a silica gel column chromatography (200-300 mesh) and was eluted in a gradient manner with $\mathrm{CH}_{2} \mathrm{Cl}_{2} / \mathrm{MeOH}$ (from $50: 1$ to $3: 1$, $v / v$ ) to yield three subfractions (Fr.1-Fr.3). Fr.2 was separated by Sephadex LH-20 (MeOH) to obtain two subfractions (Fr.2-1-Fr.2-2). Fr.2-1 was isolated by preparative TLC $\left(\mathrm{EtOA}_{\mathrm{C}}-\mathrm{MeOH}-\mathrm{H}_{2} \mathrm{O}, 5: 1: 0.9\right)$ to obtain compound $\mathbf{1 4}$ $(2.1 \mathrm{mg})$. Fr.2-2 was further purified by semipreparative HPLC (MeOH- $\left.\mathrm{H}_{2} \mathrm{O}, 35: 65\right)$ to obtain $\mathbf{1 5}$ (2.0 mg). Fr.3 was partly separated by Sephadex LH-20 $(\mathrm{MeOH})$ to obtain some subfractions, compounds $\mathbf{1}(420.0 \mathrm{mg})$ and $\mathbf{5}(10.2 \mathrm{mg})$. One of the subfractions was subjected to preparative TLC $\left(\mathrm{EtOA}_{\mathrm{C}}-\mathrm{MeOH}-\mathrm{H}_{2} \mathrm{O}, 5: 1: 0.9\right)$ to obtain compounds 11 $(2.1 \mathrm{mg})$ and $12(2.2 \mathrm{mg})$. Another part of Fr.3 was chromatographed on a reversed-phase ODS by gradient elution with $\mathrm{MeOH} / \mathrm{H}_{2} \mathrm{O}(10 \longrightarrow 70 \%, v / v)$ to obtain five subfractions (Fr.3.1-Fr.3.5). Fr.3.3 was separated repeatedly with Sephadex LH-20 (MeOH) to obtain two subfractions (Fr.3.3.1-Fr.3.3.2). Fr.3.3.1 was further purified through preparative TLC (EtOAc-MeOH- $\left.\mathrm{H}_{2} \mathrm{O}, 5: 1: 0.9\right)$ to obtain compound $4(8.3 \mathrm{mg})$. Fr.3.3.2 was chromatographed over semipreparative HPLC $\left(\mathrm{MeOH}-\mathrm{H}_{2} \mathrm{O}, 35: 65\right)$ to obtain compound $3(2.3 \mathrm{mg})$. Fr.3.4 was separated by semipreparative HPLC $\left(\mathrm{MeOH}-\mathrm{H}_{2} \mathrm{O}, 40: 60\right)$ to obtain compound $2(4.4 \mathrm{mg})$.

The $n$-butanol fraction $(25.3 \mathrm{~g})$ was subjected to a reversed-phase ODS, and elution with a gradient of $\mathrm{MeOH}$ $(5 \longrightarrow 50 \%, v / v)$ in water to obtain four subfractions (Fr.1Fr.4). Compounds $9(6.2 \mathrm{mg})$ and $\mathbf{1 7}(5.2 \mathrm{mg})$ were obtained from Fr.1 by preparative TLC (EtOAc- $\mathrm{MeOH}-\mathrm{H}_{2} \mathrm{O}, 5: 1: 0.9$ ).

1,2 , 3, 4, 6-Penta- $O$-galloyl- $\beta$-D-glucoside (1): maple powder; ${ }^{1} \mathrm{H}$ and ${ }^{13} \mathrm{C}$ NMR data matched literature values [14].

1, 2, 3, 4, 6-Penta-O-galloyl- $\alpha$-D-glucoside (2): maple powder; ${ }^{1} \mathrm{H}$ and ${ }^{13} \mathrm{C}$ NMR data were in agreement well with published data [15].

$1,2,3$, 6-Tetra- $O$-galloyl- $\beta$-D-glucoside (3): white powder; ${ }^{1} \mathrm{H}$ and ${ }^{13} \mathrm{C}$ NMR data were similar to the literature values of 1, 2, 3, 6-Tetra- $O$-galloyl- $\beta$-D-glucoside [16].

1-O-(3, 4, 5-Trihydroxybenzoyl)- $\beta$-D-glucoside (4): white powder; ${ }^{1} \mathrm{H}$ and ${ }^{13} \mathrm{C}$ NMR data were in agreement with the literature values of $1-O-(3,4,5$-Trihydroxybenzoyl)- $\beta$-Dglucose [17].

Methyl galate (5): yellow Amorphous powder; ${ }^{1} \mathrm{H}$ and ${ }^{13} \mathrm{C}$ NMR data agreed well with literature values [18].

Gallic acid (6): white needle crystal; ${ }^{1} \mathrm{H}$ and ${ }^{13} \mathrm{C}$ NMR data matched literature values $(\mathrm{Ni}$, Liang, Huang, Chen, Zou, Li, et al., 2019).

3,4-Dihydroxybenzoic acid (7): colorless needle crystal; ${ }^{1} \mathrm{H}$ and ${ }^{13} \mathrm{C}$ NMR data were identical to those recorded by Chunhakant and Chaicharoenpong [19]. 
4-Hydroxybenzoic acid (8): colorless needle crystal; ${ }^{1} \mathrm{H}$ and ${ }^{13} \mathrm{C}$ NMR data were identical to those reported [20].

1-Glycerol gallate (9): pale yellow powder; ${ }^{1} \mathrm{H}$ and ${ }^{13} \mathrm{C}$ NMR data were in agreement with the literature values [21].

Ethyl gallate (10): colorless powder; ${ }^{1} \mathrm{H}$ and ${ }^{13} \mathrm{C} \mathrm{NMR}$ data were similar to those recorded by Chen et al. [22].

Ferulic acid (11): white powder; ${ }^{1} \mathrm{H}$ and ${ }^{13} \mathrm{C}$ NMR data matched literature values [23].

Caffeic acid (12): white needle crystal; ${ }^{1} \mathrm{H}$ and ${ }^{13} \mathrm{C}$ NMR data were in agreement with those dealt with in the literature [24].

Quercetin (13): yellow powder; ${ }^{1} \mathrm{H}$ and ${ }^{13} \mathrm{C}$ NMR data were identical to those reported [25].

Genistein (14): pale yellow powder; ${ }^{1} \mathrm{H}$ and ${ }^{13} \mathrm{C} \mathrm{NMR}$ data matched literature values [26].

Gallocatechin (15): yellow amorphous powder; ${ }^{1} \mathrm{H}$ and ${ }^{13} \mathrm{C}$ NMR data were identical to those recorded by Foo, Lu, Molan, Woodfield, and McNabb [27].

Epicatechin (16): white powder; ${ }^{1} \mathrm{H}$ and ${ }^{13} \mathrm{C}$ NMR data were in agreement well with published data (M. [28]).

Hexyl- $\beta$-D-glucoside (17): pale yellow powder; ${ }^{1} \mathrm{H}$ and ${ }^{13} \mathrm{C}$ NMR data agreed well with literature values [29].

2.6. Determination of Antioxidant and $\alpha$-Glucosidase Inhibitory Activities of the Isolated Compounds. The antioxidant and $\alpha$-glucosidase inhibitory activities of each isolated compound at concentrations ranging from 15.625 to $500 \mu \mathrm{M}$ (DPPH) and from 125 to $2000 \mu \mathrm{M}$ ( $\alpha$-glucosidase inhibitory), respectively, were determined using the methods described in Section 2.3.

2.7. Inhibitory Kinetic Analysis. The kinetic mechanisms of active compounds $\mathbf{1}$ and $\mathbf{2}$ towards $\alpha$-glucosidase were determined by the graphical views of Dixon and Lineweaver-Burk plots [30]. The concentration ranges for the substrates were 0.8-5.0 mM. The concentration of the enzyme was kept constant at $1.3 \mathrm{U} / \mathrm{mL}$. Lineweaver-Burk plots were established to evaluate the type of inhibition. Dixon plots were used to calculate inhibitory constant $\left(K_{\mathrm{i}}\right)$ values of the tested compounds. Each kinetic analysis was implemented in triplicate from which mean $K_{\mathrm{i}}$ values.

2.8. Molecular Docking Calculation. To investigate the interaction between active compounds and $\alpha$-glucosidase, molecular simulations were generated by using AutoDock Vina (version 1.1.2). The crystal structure of isomaltase from Saccharomyces cerevisiae (PDB ID: 3A4A) was diffusely used in the molecular docking analysis [31]. The 3D structure of compounds 1-2 and acarbose was built by ChemBioDraw Ultra 14.0 and energy minimized by ChemBio3D Ultra 14.0 software. The ligands were modified for docking by incorporating nonpolar hydrogen and setting revolvable bonds. As for receptor, all the water molecules were removed and necessary hydrogen atoms were added to the protein. Compounds $\mathbf{1}$ and $\mathbf{2}$ and acarbose were considered fully flexible. The grid for docking was formed using $X-, Y$-, and $Z$-axes. The docking runs were performed using the Lamarckian genetic algorithm (LGA). In addition, acquiescent arguments were used unless otherwise indicated. The docked formation
TABLE 1: Antioxidant and $\alpha$-glucosidase inhibitory activities of the $60 \%$ ethanol extract and fractions from mango seed kernel.

\begin{tabular}{lcc}
\hline Extract and fractions & $\begin{array}{c}\mathrm{DPPH} \text { assay } \\
\mathrm{IC}_{50}{ }^{\mathrm{A}}(\mu \mathrm{g} / \mathrm{mL})\end{array}$ & $\begin{array}{c}\alpha \text {-Glucosidase } \\
\text { inhibitory }\end{array}$ \\
\hline $\mathrm{IC}_{50}{ }^{\mathrm{A}}(\mu \mathrm{g} / \mathrm{mL})$
\end{tabular}

${ }^{\mathrm{A}}$ Data were represented as the mean value $\pm \mathrm{SD}, n=3$. Values followed by different letters are significantly different $(p \leq 0.05) .{ }^{\mathrm{B}}$ The test concentrations ranged from 62.5 to $1000 \mu \mathrm{g} / \mathrm{mL}$. ${ }^{C}$ Positive control (DPPH assay). ${ }^{D}$ Positive control ( $\alpha$-glucosidase inhibitory effect).

with the lowest energy value between $\alpha$-glucosidase and active compounds was obtained and visually evaluated using PyMoL 1.7.6 software (http://www.pymol.org/).

2.9. Statistical Analysis. The statistical analysis was conducted by the Statistical Program for Social Sciences (SPSS; Chicago, IL) version 13.0 for Windows. All the data were expressed as mean values \pm standard deviation $(n=3)$. Statistical significance between groups was assessed by using oneway analysis of variance followed by the LSD test in the condition of variance homogeneity and Dunnett's T3 test in the condition of variance heterogeneity. Differences were considered significant at $p<0.05$.

\section{Results and Discussion}

3.1. Antioxidant and $\alpha$-Glucosidase Inhibitory Activities Evaluation of the Extract and Fractions from Mango Seed Kernel. In this study, the $60 \%$ ethanol extract was obtained from the mango seed kernel by ultrasonic extraction, and the extract solution was concentrated in vacuo. The crude extract was successively partitioned with petroleum ether, dichloromethane, ethyl acetate, and $n$-butanol. After that, in vitro antioxidant and $\alpha$-glucosidase inhibitory activities were evaluated (Table 1). Among the extract and fractions, petroleum ether and dichloromethane fractions showed moderate inhibitory activity against $\alpha$-glucosidase $\left(\mathrm{IC}_{50}\right.$ of 80.10 and $83.58 \mu \mathrm{g} / \mathrm{mL}$, respectively). The ethyl acetate fraction was found to possess the best antioxidant and $\alpha$-glucosidase inhibitory capacity $\left(\mathrm{IC}_{50}\right.$ of 15.78 and $53.33 \mu \mathrm{g} / \mathrm{mL}$, respectively). The $n$-butanol fraction showed a positive $\mathrm{DPPH}$ radical scavenging activity $\left(\mathrm{IC}_{50}\right.$ of $\left.44.06 \mu \mathrm{g} / \mathrm{mL}\right)$. Consequently, in order to further clarify the chemical basis in active fractions, we performed additional studies.

3.2. GC-MS Analysis of the Bioactive Fraction (the Petroleum Ether Fraction) from Mango Seed Kernel. GC-MS chromatogram of the petroleum ether fraction of mango seed kernel revealed 23 components were detected during retention time 60 min (Figure 1(a)). Mass spectral fingerprint of compounds 


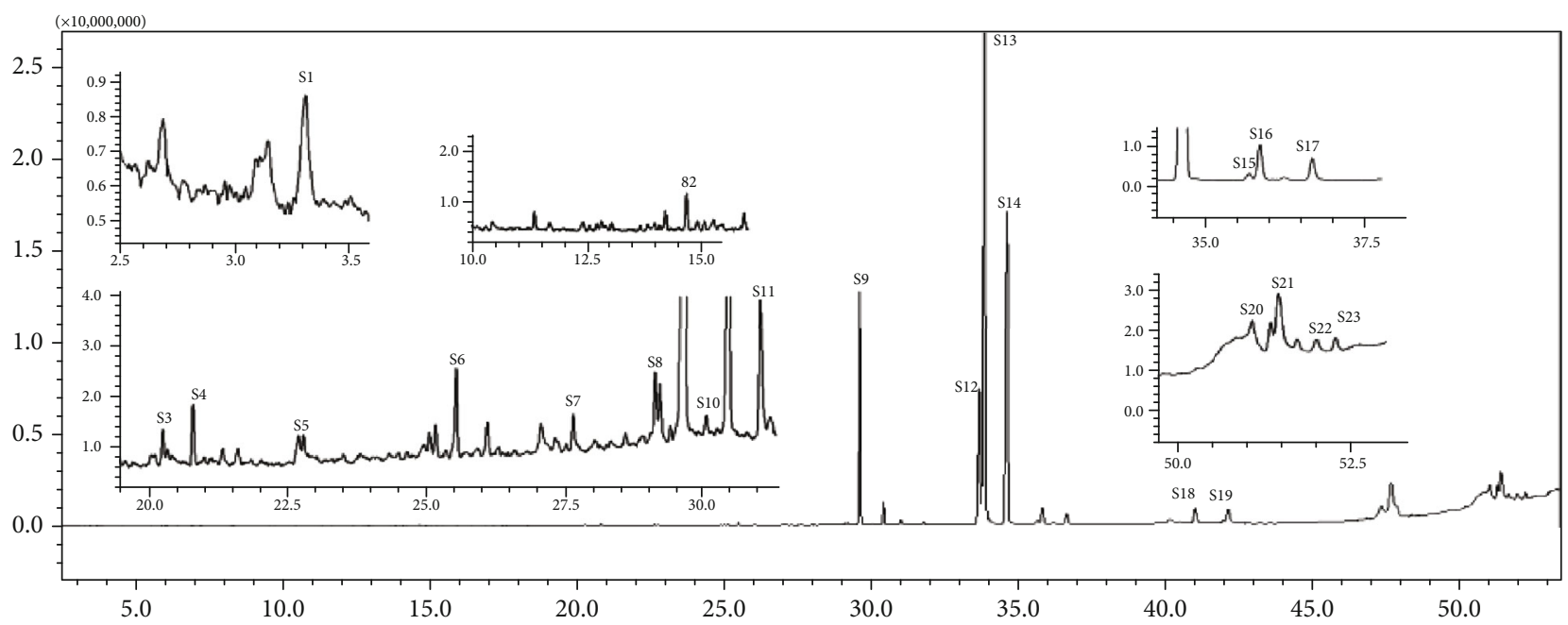

(a)

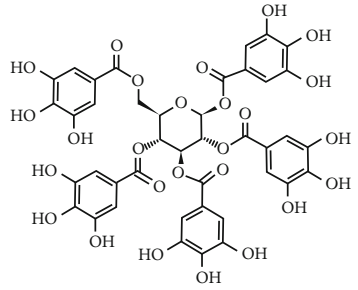

1

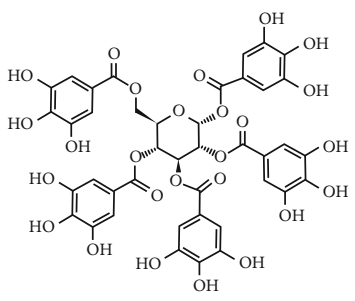

2

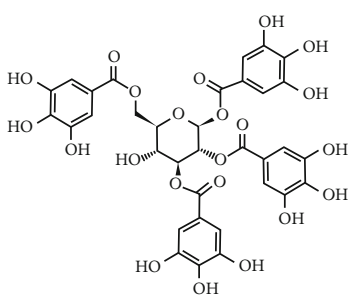

3<smiles>O=C(OC1OC(CO)[C@H](O)[C@H](O)[C@H]1O)c1cc(O)c(O)c(O)c1</smiles>

4<smiles>CC(=O)c1cc(O)c(O)c(O)c1</smiles>

5<smiles>O=C(O)/C=C/c1ccc(O)c(O)c1</smiles>

12<smiles>O=C(O)c1cc(O)c(O)c(O)c1</smiles>

6<smiles>O=C(O)c1ccc(O)c(O)c1</smiles>

7<smiles>O=C(O)c1ccc(O)cc1</smiles>

8<smiles>O=C(OCC(O)CO)c1cc(O)c(O)c(O)c1</smiles>

9<smiles>OC1=C(c2cc(O)c(O)c(O)c2)Oc2cc(O)cc(O)c2C1</smiles>

15<smiles>CCOC(=O)c1cc(O)c(O)c(O)c1</smiles>

10<smiles>Oc1cc(O)c2c(c1)O[C@H](c1ccc(O)c(O)c1)C[C@H]2O</smiles>

16<smiles>COc1cc(/C=C/C(=O)O)ccc1O</smiles>

11

(b)

FIGURE 1: GC-MS chromatogram of the petroleum ether fraction (a) and structures of other active fractions (b) from mango seed kernel.

was confirmed by molecular weight and data library (Table 2). Among all the identified components, eicosane, 9-hexadecenoic acid methyl ester, 9-octadecenoic acid methyl ester, and (Z)-3-(heptadec-10-en-1-yl) phenol had never been reported in natural products before and total compounds in the petroleum ether fraction of mango seed kernel were reported for the first time. In addition, specific GC-MS assays also showed that components S9, S12, S13, and S14 were its main ingredients, as reported for this compound making up to $10.3 \%, 9.31 \%, 39.11 \%$, and $23.67 \%$ of this fraction. The biological activities of main components have been reported in many references. The findings of studies $[32,33]$ showed that hexadecanoic acid methyl ester, (9Z,12Z)-9,12-octadecadienoic acid methyl ester, octadecanoic acid methyl ester, and (E)-9-octadecenoic acid methyl ester both had significant antioxidant and $\alpha$-glucosidase inhibitory functions. In addition, $(9 Z, 12 Z)-9,12$-octadecadienoic acid methyl ester and (E)-9-octadecenoic acid methyl ester also showed superior activity against human cancer cell line [34]. Besides this, in the references, the biological activities of other identified components in the petroleum ether fraction of mango seed kernel have been reported. The study of Das, Vasudeva, and Sharma [35] proved that methyl tetradecanoate was a membrane stabilizer and a source of nutrients for protoplasm. Pasquer, Isidore, Zarn, and Keller [36] and Malamy and Klessig [37] suggested that application of 2,4-bis(1,1-dimethylethyl)phenol induced expression of PR genes and promoted resistance to bacterial, oomycete, viral, and fungal pathogens in various monocotyledonous and dicotyledonous plants. Meanwhile, the antibacterial effect of 2, 4-bis(1,1-dimethylethyl)phenol appeared to correlate with the antioxidant capacity recorded to the compound, as it 


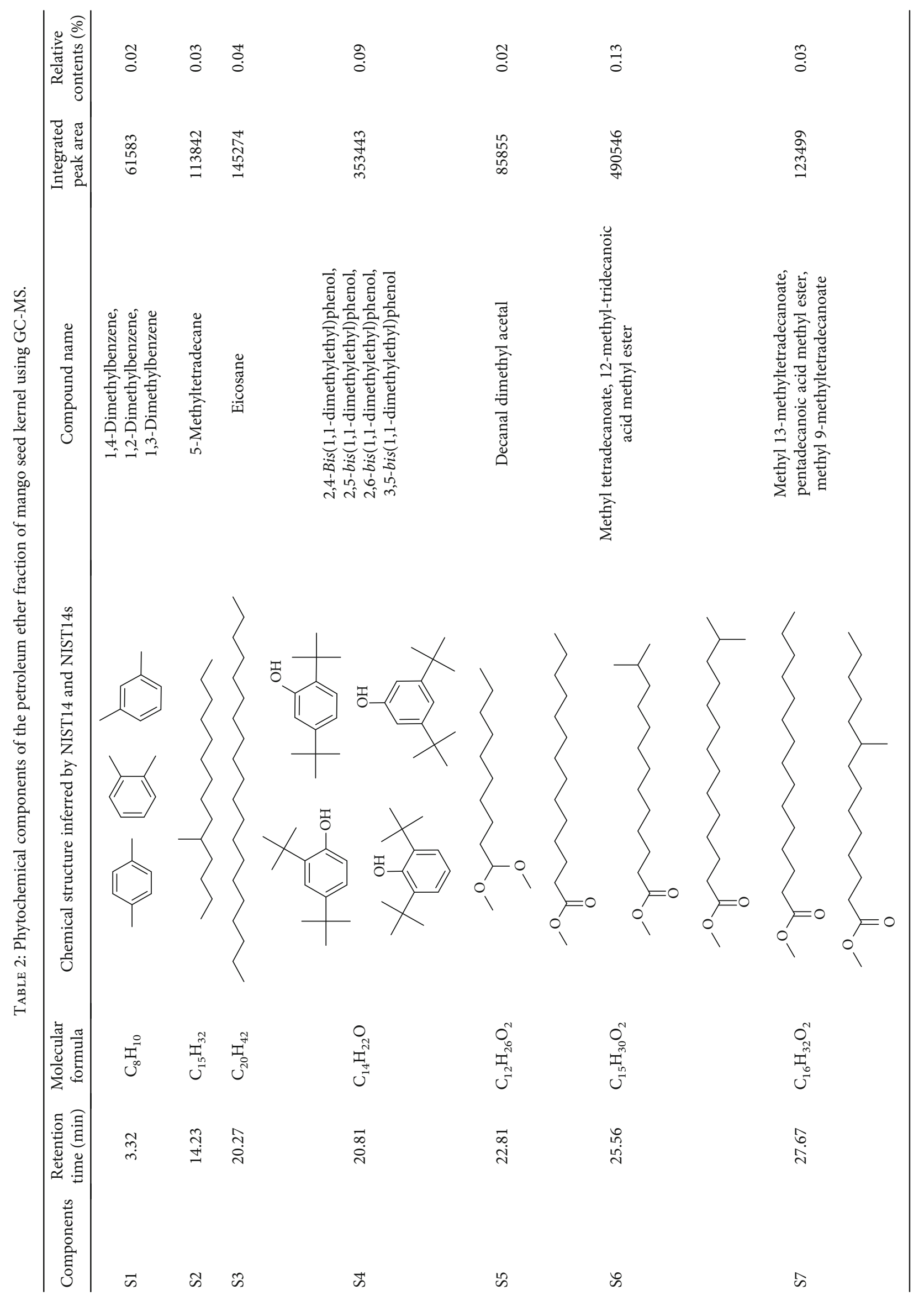




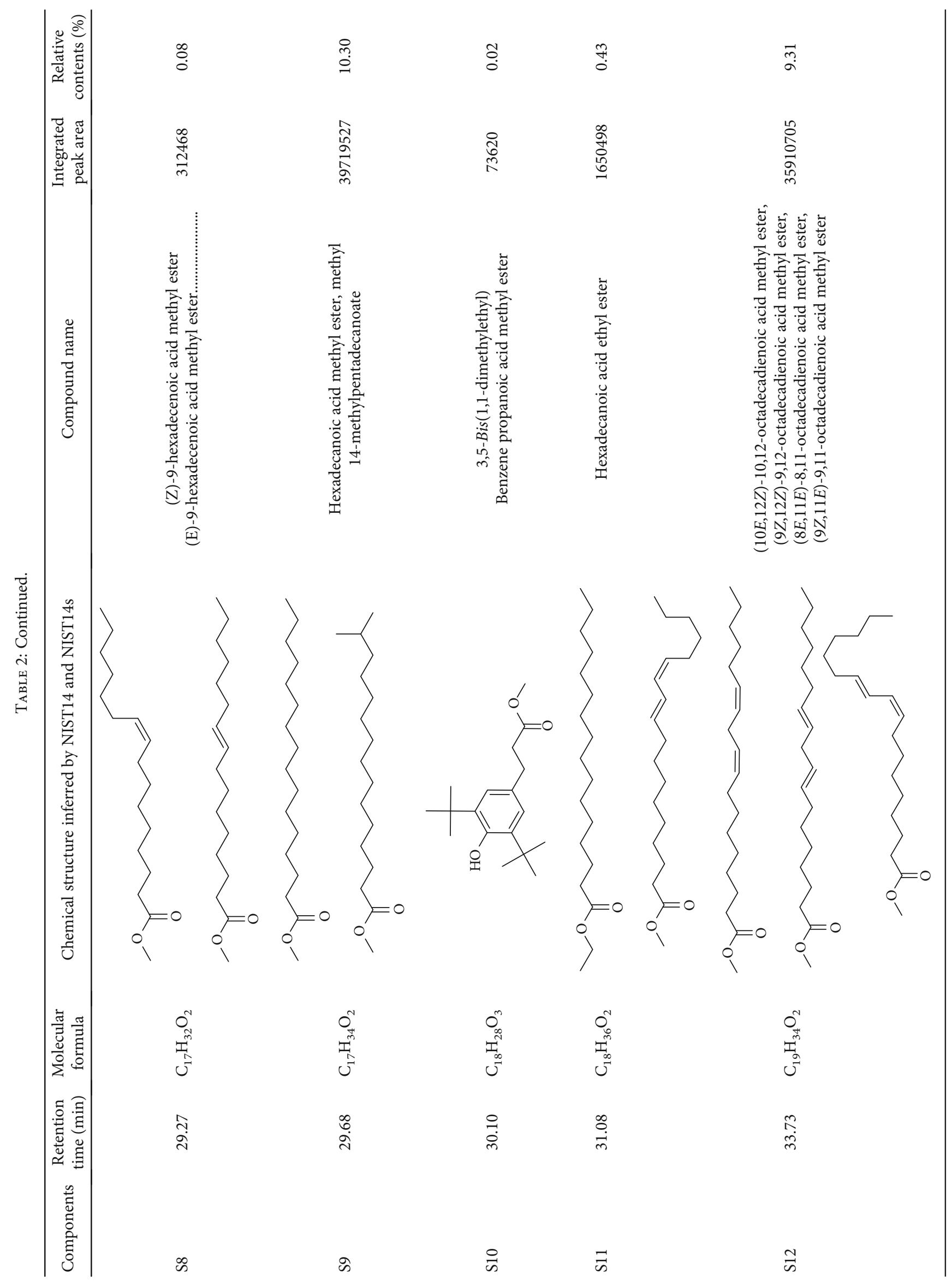




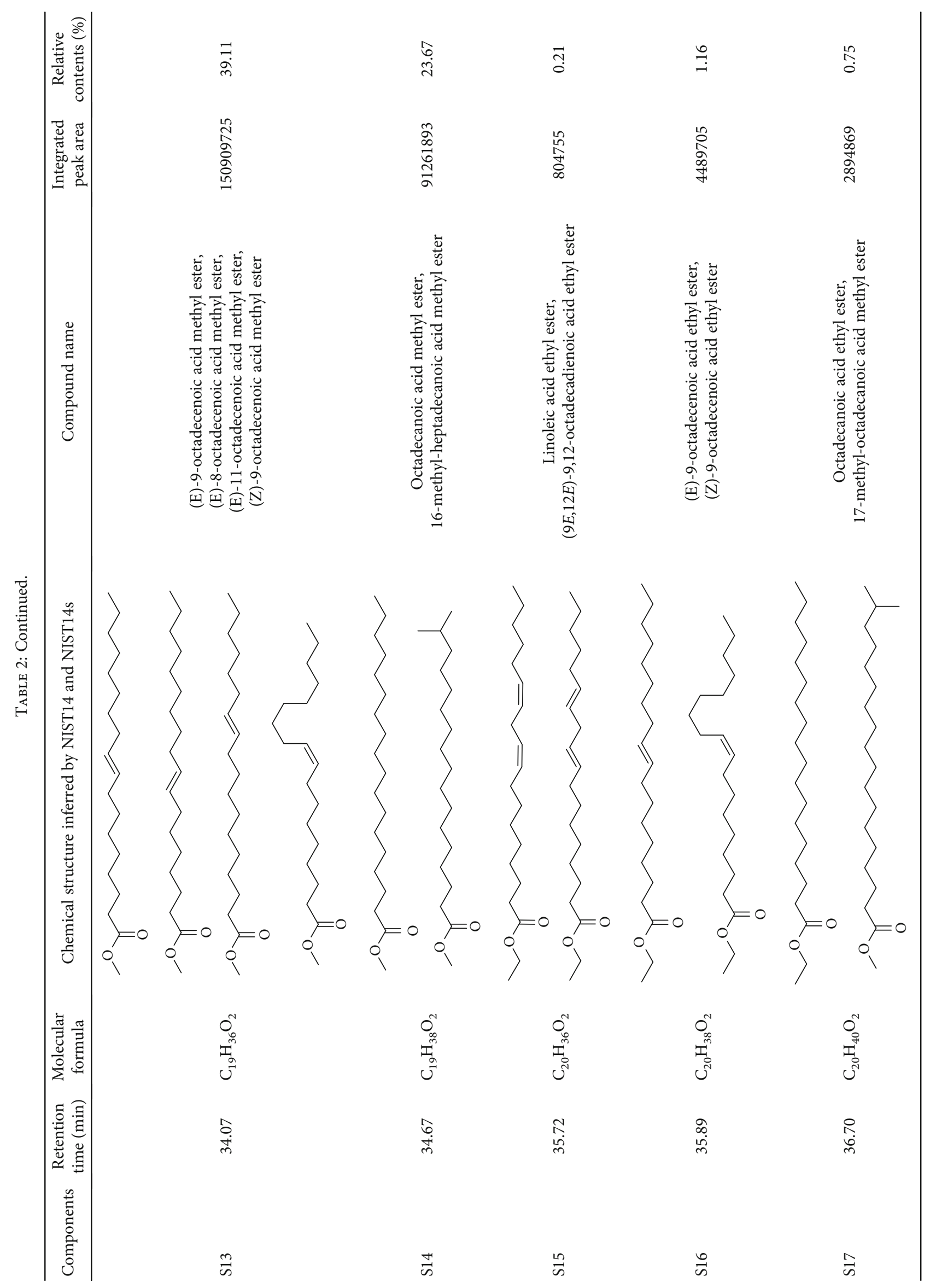




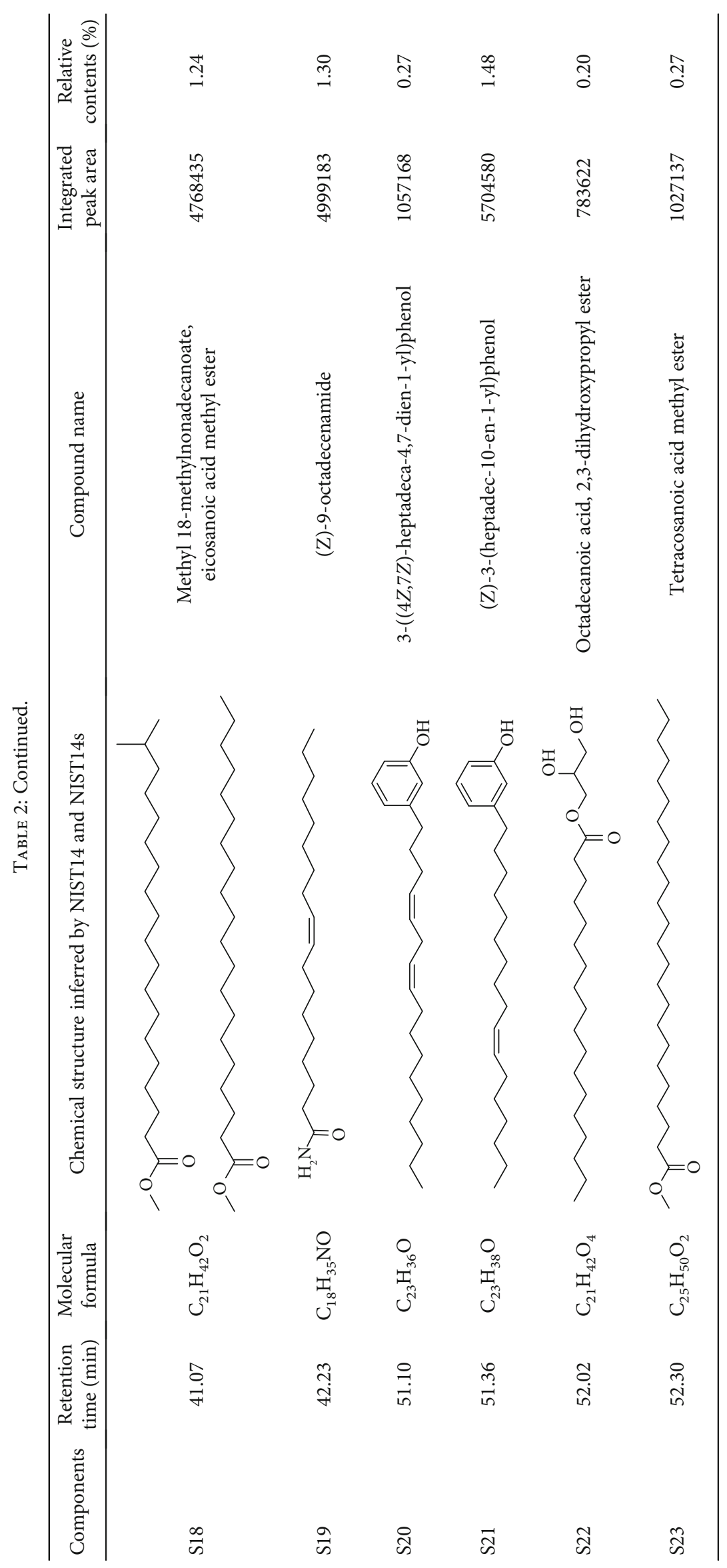


TABle 3: Antioxidant and $\alpha$-glucosidase inhibitory activities of the isolated compounds from mango seed kernel.

\begin{tabular}{|c|c|c|c|c|}
\hline Compounds & $\begin{array}{c}\text { DPPH assay }{ }^{\mathrm{B}} \\
\mathrm{IC}_{50}{ }^{\mathrm{A}}(\mu \mathrm{M}) \\
\end{array}$ & $\begin{array}{c}\alpha \text {-Glucosidase inhibitory } \\
\text { IC }_{50}{ }^{\mathrm{A}}(\mu \mathrm{M})\end{array}$ & Inhibition mode $^{\mathrm{D}}$ & $K_{\mathrm{i}}(\mathrm{nM})^{\mathrm{E}}$ \\
\hline 1 & $2.93 \pm 1.06^{j}$ & $0.60 \pm 0.36^{\mathrm{e}}$ & Noncompetitive & $732.95 \pm 0.22$ \\
\hline 2 & $22.31 \pm 0.74^{\mathrm{i}}$ & $0.07 \pm 0.10^{\mathrm{e}}$ & Competitive & $98.37 \pm 0.31$ \\
\hline 3 & $23.68 \pm 0.52^{\mathrm{i}}$ & $243.30 \pm 1.43^{\mathrm{c}}$ & - & - \\
\hline 4 & $52.82 \pm 0.93^{\mathrm{d}}$ & $>500$ & - & - \\
\hline 5 & $32.26 \pm 0.48^{\mathrm{h}}$ & $>500$ & - & - \\
\hline 6 & $37.81 \pm 2.52^{\mathrm{f}}$ & $313.03 \pm 3.71^{\mathrm{b}}$ & - & - \\
\hline 7 & $38.19 \pm 1.03^{f}$ & $425.12 \pm 31.50^{\mathrm{a}}$ & - & - \\
\hline 9 & $>500$ & $>500$ & - & - \\
\hline 10 & $37.97 \pm 1.94^{\mathrm{f}}$ & $>500$ & - & - \\
\hline 11 & $94.99 \pm 2.41^{\mathrm{b}}$ & $>500$ & - & - \\
\hline 12 & $36.91 \pm 0.30^{\mathrm{g}}$ & $>500$ & - & - \\
\hline 13 & $59.97 \pm 0.82^{c}$ & $137.94 \pm 7.07^{\mathrm{d}}$ & - & - \\
\hline 16 & $40.15 \pm 0.82^{\mathrm{e}}$ & $>500$ & - & - \\
\hline Ascorbic acid ${ }^{F}$ & $116.63 \pm 4.16^{\mathrm{a}}$ & - & - & - \\
\hline Acarbose $^{\mathrm{G}}$ & - & $0.11 \pm 0.01^{\mathrm{e}}$ & - & - \\
\hline
\end{tabular}

${ }^{\mathrm{A}}$ Data were represented as the mean value \pm SD, 6 . Values followed by different letters are significantly different $(p \leq 0.05) .{ }^{\mathrm{B}}$ The test concentrations ranged from 15.625 to $500 \mu \mathrm{M}$. ${ }^{C}$ The test concentrations ranged from 125 to $2000 \mu \mathrm{M}$. ${ }^{\mathrm{D}}$ Determined by Lineweaver-Burk plots. ${ }^{\mathrm{E}}$ Determined by Dixon plots. ${ }^{\mathrm{F}}$ Positive control (DPPH assay). ${ }^{\mathrm{G}}$ Positive control ( $\alpha$-glucosidase inhibitory effect).

restrained the production of ROS in both Phytophthora and Aspergillus cinnamomi [38].

3.3. Isolation and Purification of Compounds in Active Fractions from Mango Seed Kernel. Based on the activity results of extract and all fractions, dichloromethane, ethyl acetate, and $n$-butanol fractions were applied to further isolation and purification by chromotography on Sephadex LH20 column, silica gel column, ODS, and preparative TLC, as well as semipreparative HPLC, et al. Finally, 17 compounds were obtained. Their structures were identified as $1,2,3,4$, 6-penta-O-galloyl- $\beta$-D-glucoside (1) $[14], 1,2,3,4,6$ penta-O-galloyl- $\alpha$-D-glucoside (2) [15], 1, 2, 3, 6-tetra-Ogalloyl- $\beta$-D-glucoside (3) [16], 1-O-(3, 4, 5-trihydroxybenzoyl)- $\beta$-D-glucoside (4) [17], methyl galate (5) [18], gallic acid (6) [39], 3,4-dihydroxybenzoic acid (7) [19], 4hydroxybenzoic acid (8) [20], 1-glycerol gallate (9) [21], ethyl gallate (10) (H. [22]), ferulic acid (11) [23], caffeic acid (12) [24], quercetin (13) [25], genistein (14) [26], gallocatechin (15) [27], epicatechin (16) (M. [28]), and hexyl- $\beta$-D-glucoside (17) [29] by comparing their NMR spectroscopic data with data reported in the above references. Compounds 2 , 9, 15, and 17 were isolated from the genus Mangifera for the first time.

3.4. Determination of the DPPH Scavenging Activity of the Isolated Compounds. 13 isolated compounds from mango seed kernel were assayed for the antioxidant activity (Table 3). Most of the isolated phenolic compounds showed strong antioxidant activity. The relative order of compounds 1-4 in DPPH radical scavenging capacity was found to be compound $1 \quad\left(\mathrm{IC}_{50}=2.93 \pm 1.06 \mu \mathrm{M}\right)>2 \quad\left(\mathrm{IC}_{50}=22.31 \pm\right.$ $0.74 \mu \mathrm{M})>3 \quad\left(\mathrm{IC}_{50}=23.68 \pm 0.52 \mu \mathrm{M}\right)>4 \quad\left(\mathrm{IC}_{50}=52.82 \pm\right.$
$0.93 \mu \mathrm{M})>$ ascorbic acid $\left(\mathrm{IC}_{50}=116.63 \pm 4.16 \mu \mathrm{M}\right)$, which suggested that the number of the galloyl moiety played a crucial role in the antioxidant activity, the more it was, the stronger antioxidant activity would be exhibited. Meanwhile, compound 1 showed higher radical scavenging activity than 2. Hence, compound 1 might have a better spatial configuration than $\mathbf{2}$ to promote the DPPH radical scavenging activity. The relative order of compounds 5, 6, 9, and 10 in DPPH radical scavenging capacity was found to be compound $5 \quad\left(\mathrm{IC}_{50}=32.26 \pm 0.48 \mu \mathrm{M}\right)>6 \quad\left(\mathrm{IC}_{50}=37.81 \pm 2.52 \mu \mathrm{M}\right)>$ $10\left(\mathrm{IC}_{50}=37.97 \pm 1.94 \mu \mathrm{M}\right)>9\left(\mathrm{IC}_{50}>500 \mu \mathrm{M}\right)$, which suggested that the substitution of glycerin at the hydroxyl group of the carboxylic acid in gallic acid significantly reduced $\mathrm{DPPH}$ radical scavenging ability. Compound $12\left(\mathrm{IC}_{50}=\right.$ $36.91 \pm 0.30 \mu \mathrm{M})$ exhibited moderate antioxidant activity, which was nearly threefold higher than compound $\mathbf{1 1}$ $\left(\mathrm{IC}_{50}=94.99 \pm 2.41 \mu \mathrm{M}\right)$, respectively. Therefore, the methoxy group at aromatic rings was not beneficial for the radical scavenging activity.

\subsection{Determination of the $\alpha$-Glucosidase Inhibitory Activity of} the Isolated Compounds. $\alpha$-Glucosidase inhibitors could significantly reduce postprandial blood glucose levels in patients with type II diabetes mellitus and reduce diabetic complications. The $\alpha$-glucosidase inhibitory activities of the extract and four fractions had been analyzed above. As shown in Table 3, compounds 2 ( $\mathrm{IC}_{50}=0.07 \pm 0.1 \mu \mathrm{M}$ ) exhibited the strongest inhibitory effect on $\alpha$-glucosidase, which was similar to that of acarbose $\left(\mathrm{IC}_{50}=0.11 \pm 0.01 \mu \mathrm{M}\right)$, followed by compound $1 \quad\left(\mathrm{IC}_{50}=0.6 \pm 0.36 \mu \mathrm{M}\right), 3 \quad\left(\mathrm{IC}_{50}=243.30 \pm\right.$ $1.43 \mu \mathrm{M})$, and $4\left(\mathrm{IC}_{50}>500 \mu \mathrm{M}\right)$. It could be concluded that compound $\mathbf{2}$ might have a better spatial configuration than $\mathbf{1}$ to promote the activity, and the amount of the galloyl moiety 


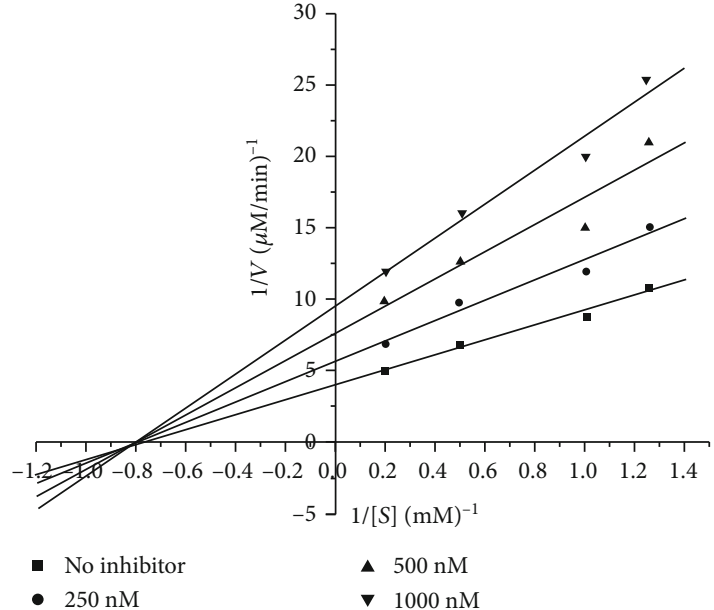

(a)

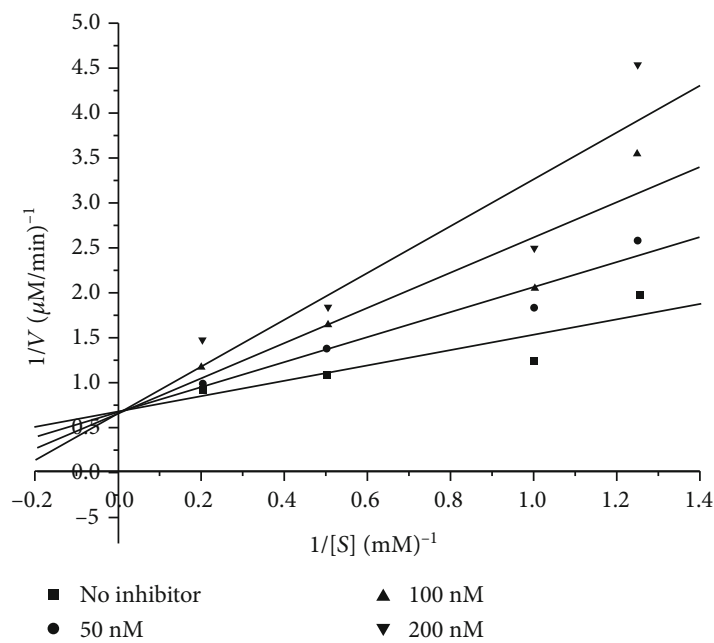

(c)

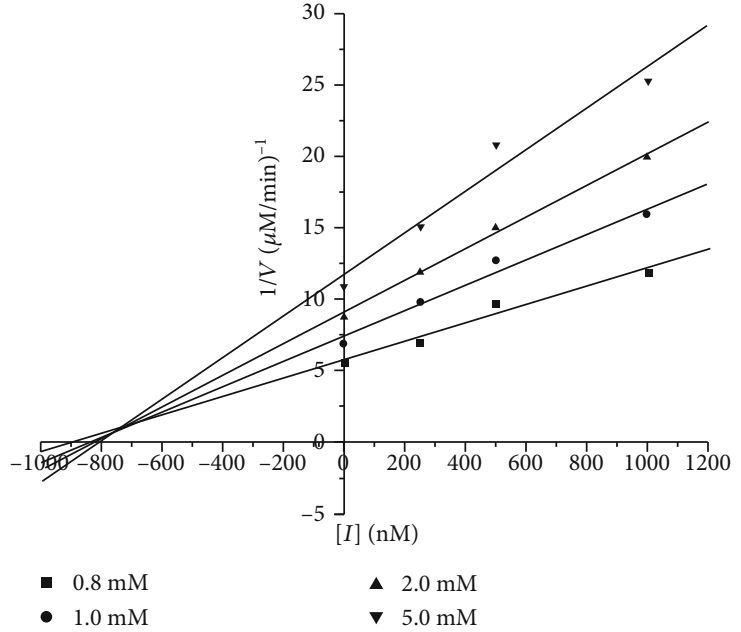

(b)

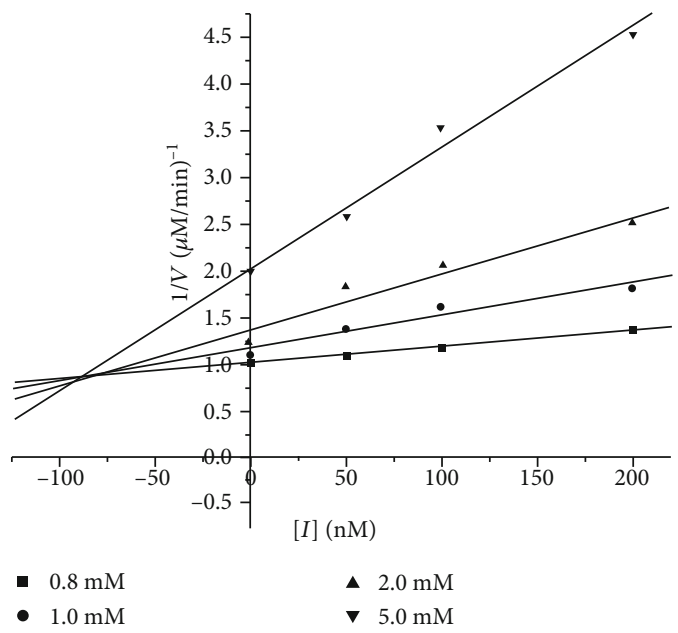

(d)

Figure 2: Lineweaver-Burk plots and Dixon plots for the inhibition of $\alpha$-glucosidase by compounds 1 (a, b) and 2 (c, d).

played a crucial role in $\alpha$-glucosidase inhibition. Compound $6\left(\mathrm{IC}_{50}=313.03 \pm 3.71 \mu \mathrm{M}\right)$ showed low $\alpha$-glucosidase inhibitory activity. Compounds 5, 9, and 10 were reported no inhibitory activity. These results indicated that the substitution of methoxyl, ethyoxyl, and glyceryl at the hydroxyl group on the carboxylic acid of gallic acid could reduce the inhibition of $\alpha$-glucosidase. Meanwhile, compound $\mathbf{6}$ exhibited higher $\alpha$-glucosidase inhibitory potential than 7 $\left(\mathrm{IC}_{50}=425.12 \pm 31.50 \mu \mathrm{M}\right)$. From this study, it indicated that increasing the number of hydroxyl group on the aromatic ring could enhance the inhibitory activity of $\alpha$-glucosidase.

3.6. $\alpha$-Glucosidase Inhibition Kinetics of Compounds $\mathbf{1}$ and $\mathbf{2}$. Compounds 1 and $\mathbf{2}$ both had strong inhibitory activities on $\alpha$-glycosidase, especially 2 . Therefore, it was necessary to investigate the inhibition types and calculate the inhibition kinetics constants $\left(K_{\mathrm{i}}\right)$. Results of enzyme kinetics study were performed by using Dixon plots and Lineweaver-Burk plots. The results were displayed in Table 3 and Figure 2. In Figure $2, K_{\mathrm{m}}$ values of $\alpha$-glucosidase in the existence of $\mathbf{1}$ did not change but $V_{\max }$ values of $\alpha$-glucosidase with the compounds progressively reduced, pointing that $\mathbf{1}$ was in a noncompetitive inhibitor manner with the $K_{\mathrm{i}}$ value of $732.95 \pm 0.22 \mathrm{nM}$. In addition, 2 restrained $\alpha$-glucosidase in competitive manner as the $V_{\max }$ maintained constant and $K_{\mathrm{m}}$ improved. Meanwhile, $K_{\mathrm{i}}$ value of this compound was calculated as $98.37 \pm 0.31 \mathrm{nM}$. Competitive inhibitors were known to compete with substrates for the active sites of enzymes, whereas noncompetitive inhibitors primarily bind to allosteric sites of enzyme-substrate complexes [40].

3.7. Molecular Docking Studies. In order to understand how isolated compounds $\mathbf{1}$ and $\mathbf{2}$ conjugate with $\alpha$-glucosidase, molecular docking was implemented. Because of the existence of the galloyl moiety, compound 2 reached deeper the active pocket than acarbose (Figure 3 ). In the interaction of compound 2 with $\alpha$-glucosidase, 2 was encompassed by the residues VAL-232, PHE-303, PHE-178, VAL-216, GLN279, LYS-156, LEU-313, ASP-307, PHE-321, VAL-308, and ALA-329. In addition, some active hydroxyl groups were involved in the formation of hydrogen bonds, such as the galloyl at the $3-\mathrm{OH}$ of sugar moiety at the C-1 and C-6 with side 


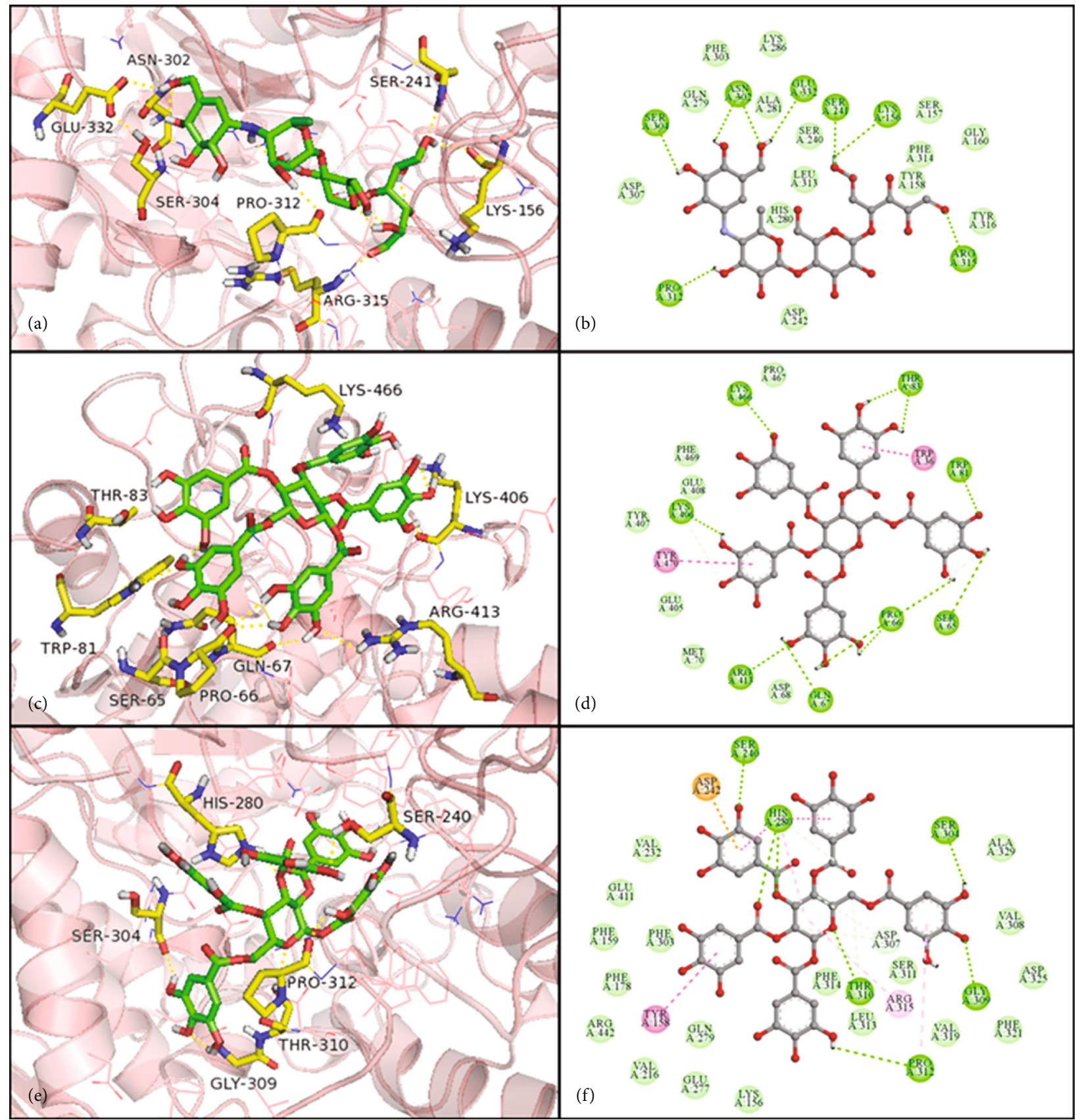

Figure 3: The binding modes and 2D diagram of $\alpha$-glucosidase inhibition by acarbose (a, b), 1, 2, 3, 4, 6-Penta- $O$-galloyl- $\beta$-D-glucoside (1) (c, d) and 1, 2, 3, 4, 6-Penta-O-galloyl- $\alpha$-D-glucoside (2) (e, f). The small molecules were shown in green sticks, while the hydrogen bonds were shown in yellow sticks (For interpretation of the references to color in this figure legend, the reader is referred to the web version of this article.).

chains of PRO-312 and SER-304, respectively, the galloyl at the 3-O on sugar moiety at the $\mathrm{C}-3$ position and the galloyl at the $4-\mathrm{O}$ on sugar moiety at the C-6 position with side chains of SER-240 and GLY-309, and the carbonyl group on the galloyl on sugar moiety at the C-2 and oxygen atom on the sugar moiety with HIS-280 and THR-310, respectively. Meanwhile, $\pi-\pi$ T-shaped, $\pi$-alkyl, and electrostatic interactions facilitated the tight bonding between the enzyme and compound 2. By contrast, acarbose could only form seven hydrogen bonds.
To investigate the allosteric site of the $\alpha$-glucosidase bond with noncompetitive inhibitors (1), we implemented blind docking by establishing a grid involved in all enzymes. Compound $\mathbf{1}$ was surrounded by a number of catalytic amino acid residues (Figure 3), including PRO-467, PHE-469, GLU-408, MET-70, and ASP-68. Eight hydrogen bonds were present between the galloyl at the $1,2,3-\mathrm{OH}$ and $1-\mathrm{O}$ on sugar moiety at the $\mathrm{C}-1$ position, the galloyl at the $1-\mathrm{OH}$ on sugar moiety at the $\mathrm{C}-2$ position, the galloyl at the 1-O on sugar moiety at the $\mathrm{C}-3$ position, the galloyl at the $3,4-\mathrm{OH}$ on sugar moiety 
at the $\mathrm{C}-4$ position and the galloyl at the $3,4-\mathrm{OH}$, and $5-\mathrm{O}$ on sugar moiety at the C-6 position of compound 1 with GLN67, PRO-66, ARG-413, LYS-406, LYS-466, THR-83, TRP81 , and SER-65, respectively. The aromatic rings of the galloyl on sugar moiety at the C-4 and C-2 positions of compound 1 formed $\pi-\pi$ T-shaped and $\pi-\pi$ stacked interactions with TRP-36 and TYR-470, respectively.

In recent years, molecular docking simulations have become an important tool for understanding the interaction mode and the structure-activity relationships of ligands with receptors. The in silico research results of compounds 1 and 2 were in agreement with the $\mathrm{IC}_{50}$ data and the enzyme kinetic study in vitro. The integration of enzyme activity, kinetics, and molecular docking studies provided principle insights into the molecular basis underlying ligand binding affinity and $\alpha$-glucosidase inhibition.

\section{Conclusions}

In summary, antioxidant and $\alpha$-glucosidase inhibitory activities of the extract, fractions, and isolated compounds from mango seed kernel were first documented. The petroleum ether, dichloromethane, ethyl acetate, and $n$-butanol fractions exhibited different degrees of antioxidant and $\alpha$-glucosidase inhibitory activity. In order to further clarify the chemical basis, a total of 23 ingredients were identified by efficient and fast GC-MS analysis from the petroleum ether fraction. As far as we know, it was the first report on the detailed compounds of the petroleum ether fraction of mango seed kernel. Among all the identified components, (Z)-3-(Heptadec-10-en-1-yl) phenol, eicosane, 9-octadecenoic acid methyl ester, and 9-hexadecenoic acid methyl ester had never been reported before. In addition, 17 compounds were isolated and identified from other active fractions of mango seed kernel. 1, 2, 3, 4, 6-penta- $O$-galloyl- $\alpha$-D-glucoside (2), 1-glycerol gallate (9), gallocatechin (15), and hexyl- $\beta$-D-glucoside (17) were isolated from Mangifera for the first time. Among isolated components, 1, 2, 3, 4, 6penta- $O$-galloyl- $\beta$-D-glucoside (1) and 1, 2, 3, 4, 6-penta$O$-galloyl- $\alpha$-D-glucoside (2) showed stronger DPPH radical scavenging and $\alpha$-glucosidase inhibitory capacities than others. The structure-activity relationship has been discussed. According to the kinetic research, 2 inhibited $\alpha$-glucosidase in a competitive manner, whereas $\mathbf{1}$ acted in a noncompetitive manner. Molecular docking studies showed that compound $\mathbf{1}$ accommodated well in the allosteric site of the $\alpha$-glucosidase interacting with a number of crucial amino residues. Compound 2 reached deeper the active site pocket of $\alpha$-glucosidase than acarbose. The stability of binding was enhanced by $\pi-\pi$ T-shaped, $\pi$-alkyl, hydrogen bond, and electrostatic interactions. These results might be useful to investigate the pharmacological activity in this fruit. Meanwhile, our study provided a chemical basis for the further development and utilization of mango seed kernel in the food and medicine fields.

\section{Data Availability}

The underlying data supporting our findings can be found and generated during the study.

\section{Conflicts of Interest}

The authors declare no conflict of interest, financial or otherwise.

\section{Authors' Contributions}

Dan Yang and Xuee Chen are joint the first authors. The study conceptualization was done by Jun Yin and Zhihui Liu. Isolation and purification of compounds were conducted by Xuee Chen and Xida Liu. The data analysis was done by Dan Yang, Janxiu Zhai, and Sikai Li. Dan Yang and Xuee Chen wrote and prepared the original draft. Zhihui Liu, Jun Yin, and $\mathrm{Na}$ Han wrote, reviewed, and edited the manuscript. All authors have read and agreed to the published version of the manuscript.

\section{Supplementary Materials}

Figure S1: GC-MS chromatogram of the petroleum ether fraction from mango kernel. Figure S2 to Figure S24: GCMS spectrum of component 1 to 23. Table S1: molecular interactions of the $\alpha$-glucosidase (3A4A) active site with compounds 1 and 2. (Supplementary Materials)

\section{References}

[1] B. Lorenzati, C. Zucco, S. Miglietta, F. Lamberti, and G. Bruno, "Oral hypoglycemic drugs: pathophysiological basis of their mechanism of actionoral hypoglycemic drugs: pathophysiological basis of their mechanism of action," Pharmaceuticals, vol. 3, no. 9, pp. 3005-3020, 2010.

[2] S. H. Jo, K. S. Ha, K. S. Moon, O. H. Lee, H. D. Jang, and Y. I. Kwon, "In vitro and in vivo antihyperglycemic effects of Omija (Schizandra chinensis) fruit," International journal of molecular sciences, vol. 12, no. 2, pp. 1359-1370, 2011.

[3] S. Imran, M. Taha, N. H. Ismail et al., "Synthesis of novel flavone hydrazones: in-vitro evaluation of $\alpha$-glucosidase inhibition, QSAR analysis and docking studies," European Journal of Medicinal Chemistry, vol. 105, pp. 156-170, 2015.

[4] M. R. Bhandari, N. Jong-Anurakkun, G. Hong, and J. Kawabata, " $\alpha$-Glucosidase and $\alpha$-amylase inhibitory activities of Nepalese medicinal herb Pakhanbhed (Bergenia ciliata, Haw.)," Food Chemistry, vol. 106, no. 1, pp. 247252, 2008.

[5] M. A. T. Phan, J. Wang, J. Tang, Y. Z. Lee, and K. Ng, "Evaluation of $\alpha$-glucosidase inhibition potential of some flavonoids from Epimedium brevicornum," LWT - Food Science and Technology, vol. 53, no. 2, pp. 492-498, 2013.

[6] J. S. Johansen, A. K. Harris, D. J. Rychly, and A. Ergul, "Oxidative stress and the use of antioxidants in diabetes: linking basic science to clinical practice," Cardiovascular Diabetology, vol. 4, no. 1, p. 5, 2005.

[7] J. P. Kehrer, T. E. Tipple, J. D. Robertson, and C. V. Smith, "Free radicals and reactive oxygen species," in Reference Module in Biomedical Sciences, Elsevier, 2015.

[8] M. sDar, P. Oak, H. Chidley, A. Deshpande, A. Giri, and V. Gupta, "Nutrient and flavor content of mango (Mangifera indica L.) cultivars," Nutritional Composition of Fruit Cultivars, pp. 445-467, 2016. 
[9] C. Namngam and P. Pinsirodom, "Antioxidant properties, selected enzyme inhibition capacities, and a cosmetic cream formulation of Thai mango seed kernel extracts," Tropical Journal of Pharmaceutical Research, vol. 16, no. 1, p. 9, 2017.

[10] E. A. Irondi, G. Oboh, A. A. Akindahunsi, A. A. Boligon, and M. L. Athayde, "Phenolic composition and inhibitory activity of Mangifera indica and Mucuna urens seeds extracts against key enzymes linked to the pathology and complications of type 2 diabetes," Asian Pacific Journal of Tropical Biomedicine, vol. 4, no. 11, pp. 903-910, 2014.

[11] J. Pan, X. M. Yi, S. J. Zhang et al., "Bioactive phenolics from mango leaves (Mangifera indica L.)," Industrial Crops and Products, vol. 111, pp. 400-406, 2018.

[12] M. B. Hlila, H. Mosbah, K. Majouli et al., " $\alpha$-Glucosidase inhibition by Tunisian Scabiosa arenaria Forssk. extracts," International Journal of Biological Macromolecules, vol. 77, pp. 383389, 2015.

[13] X. Gao, J. Wei, L. Hong, S. Fan, G. Hu, and J. Jia, "Comparative analysis of chemical composition, anti-inflammatory activity and antitumor activity in essential oils from Siegesbeckia orientalis, S. glabrescens and S. pubescens with an ITS sequence analysis," Molecules, vol. 23, no. 9, p. 2185, 2018.

[14] R. T. D. Santos, L. L. Hiramoto, J. H. G. Lago, P. Sartorelli, A. G. Tempone, and E. G. Pinto, "Anti-trypanosomal activity of 1,2,3,4,6-penta-O-galloyl- $\beta$-D-glucose isolated from Plectranthus barbatus Andrews (Lamiaceae)," Quimica Nova, vol. 35, no. 11, pp. 2229-2332, 2012.

[15] M. Nishizawa, T. Yamagishi, G. Nonaka, I. Nishioka, and H. Bando, "Novel hydrolyzable tannins from Nuphar Japonicum DC," Chemical and Pharmaceutical Bulletin, vol. 30, no. 3, pp. 1094-1097, 1982.

[16] T. Okuda, T. Yoshida, and T. Hatano, "New methods of analyzing tannins," Journal of Natural Products, vol. 52, no. 1, pp. 1-31, 1989.

[17] Y. Zhang, D. L. DeWitt, S. Murugesan, and M. G. Nair, "Novel lipid-peroxidation- and cyclooxygenase-inhibitory tannins from Picrorhiza kurroa seeds," Chemistry and biodiversity, vol. 1, no. 3, pp. 426-441, 2004.

[18] D. J. Kwon and Y. S. Bae, "Chemical constituents from the stem bark of Acer barbinerve," Chemistry of Natural Compounds, vol. 47, no. 4, pp. 636-638, 2011.

[19] S. Chunhakant and C. Chaicharoenpong, "Antityrosinase, antioxidant, and cytotoxic activities of phytochemical constituents from Manilkara zapota L. bark," Molecules, vol. 24, no. 15, p. 2798, 2019.

[20] S. Swarnalatha, A. Umamaheswari, and A. Puratchikody, "Immunomodulatory activity of kaempferol 5-O- $\beta$-d-glucopyranoside from Indigofera aspalathoides Vahl ex DC. (Papilionaceae)," Medicinal Chemistry Research, vol. 24, no. 7, pp. 2889-2897, 2015.

[21] A. F. Artamonov, F. S. Nigmatullina, M. T. Aldabergenova, and B. Z. Dzhiembaev, "Synthesis of $\alpha$-monoglycerides of aromatic acids," Chemistry of Natural Compounds, vol. 35, no. 4, pp. 404-408, 1999.

[22] H. Chen, M. Li, C. Zhang et al., "Isolation and identification of the anti-oxidant constituents from Loropetalum chinense (R. Brown) oliv. based on UHPLC-Q-TOF-MS/MS," Molecules, vol. 23, no. 7, p. 1720, 2018.

[23] S. Aynur and K. Zeynep, "Phytochemical investigations on chemical constituents of Taraxacum bessarabicum (Hornem.)
Hand.-Mazz. subsp. bessarabicum (Hornem.) Hand.-Mazz," Iranian Journal of Pharmaceutical Research, vol. 18, pp. 400405, 2019.

[24] L. Zhou, D. Li, J. Wang, Y. Liu, and J. Wu, “Antibacterial phenolic compounds from the spines of Gleditsia sinensis Lam," Natural Product Research, vol. 21, no. 4, pp. 283291, 2007.

[25] B. B. Gao, G. M. She, and D. M. She, "Chemical constituents and biological activities of plants from the genus Ligustrum," Chemistry and biodiversity, vol. 10, no. 1, pp. 96-128, 2013.

[26] J. S. Yoon, S. H. Sung, J. H. Park, and Y. C. Kim, "Flavonoids from Spatholobus suberectus," Archives of pharmacal research, vol. 27, no. 6, pp. 589-592, 2004.

[27] L. Y. Foo, Y. Lu, A. L. Molan, D. R. Woodfield, and W. C. McNabb, "The phenols and prodelphinidins of white clover flowers,” Phytochemistry, vol. 54, no. 5, pp. 539-548, 2000.

[28] M. Chen and S. Yu, "Characterization of lipophilized monomeric and oligomeric grape seed flavan-3-ol derivatives," Journal of Agricultural and Food Chemistry, vol. 65, no. 40, pp. 8875-8883, 2017.

[29] L. Shuai, K. Hai-xue, Y. Okada, and O. Toru, "Chemical constituents of Bidens bipinnata (II)," Chinese Traditional and Herbal Drugs, vol. 35, no. 9, pp. 972-975, 2004.

[30] G. Renda, S. Sari, B. Barut et al., " $\alpha$-Glucosidase inhibitory effects of polyphenols from Geranium asphodeloides: inhibition kinetics and mechanistic insights through in vitro and in silico studies," Bioorganic Chemistry, vol. 81, pp. 545-552, 2018.

[31] L. Xu, W. Li, Z. Chen et al., "Inhibitory effect of epigallocatechin-3-O-gallate on $\alpha$-glucosidase and its hypoglycemic effect via targeting PI3K/AKT signaling pathway in L6 skeletal muscle cells," International Journal of Biological Macromolecules, vol. 125, pp. 605-611, 2019.

[32] A. G. Cruz, A. I. Mtz-Enríquez, L. Díaz-Jiménez et al., "Production of fatty acid methyl esters and bioactive compounds from citrus wax," Waste Management, vol. 102, pp. 48-55, 2020.

[33] R. Agada, W. A. Usman, S. Shehu, and D. Thagariki, "In vitro and in vivo inhibitory effects of Carica papaya seed on $\alpha$-amylase and $\alpha$-glucosidase enzymes," Heliyon, vol. 6, no. 3, p. e03618, 2020.

[34] F. R. Yu, X. Z. Lian, H. Y. Guo et al., "Isolation and characterization of methyl esters and derivatives from Euphorbia kansui (Euphorbiaceae) and their inhibitory effects on the human SGC-7901 cells," Journal of pharmacy and pharmaceutical sciences, vol. 8, no. 3, pp. 528-535, 2005.

[35] S. Das, N. Vasudeva, and S. Sharma, "Chemical composition of ethanol extract of Macrotyloma uniflorum (Lam.) Verdc. using GC-MS spectroscopy," Organic and Medicinal Chemistry Letters, vol. 4, no. 1, 2014.

[36] F. Pasquer, E. Isidore, J. Zarn, and B. Keller, "Specific patterns of changes in wheat gene expression after treatment with three antifungal compounds," Plant molecular biology, vol. 57, no. 5, pp. 693-707, 2005.

[37] J. Malamy and D. F. Klessig, "Salicylic acid and plant disease resistance," Plant journal, vol. 2, no. 5, pp. 643-654, 1992.

[38] R. C. María Teresa, V. G. Rosaura, C. M. Elda, and G. P. Ernesto, "The avocado defense compound phenol-2,4-bis (1,1-dimethylethyl) is induced by arachidonic acid and acts via the inhibition of hydrogen peroxide production by pathogens," Physiological and Molecular Plant Pathology, vol. 87, pp. 32-41, 2014. 
[39] L. Ni, W. Liang, W. Huang et al., "Chemical constituents of Euscaphis konishii and their inhibitory activities," Chemistry of Natural Compounds, vol. 55, no. 5, pp. 832-834, 2019.

[40] D. Şöhretoğlu, S. Sari, B. Barut, and A. Özel, "Discovery of potent $\alpha$-glucosidase inhibitor flavonols: insights into mechanism of action through inhibition kinetics and docking simulations," Bioorganic Chemistry, vol. 79, pp. 257-264, 2018. 